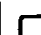

Perceptions of Ecological Risk From Natural Hazards

page 1

\title{
Perceptions of Ecological Risk From Natural Hazards
}

Lawrence J. Axelrod and Timothy McDaniels

\author{
Westwater Research Centre \\ University of British Columbia \\ and \\ Paul Slovic \\ Decision Research
}

July 10,1996 


\section{ABSTRACT}

This study examines lay perceptions. of ecological risk (risk to the health and productivity of natural environments) associated with natural hazards. Ratings of 30 specific characteristics influéncing risk judgments and one general risk assessment were obtained from 68 survey respondents for five natüral hazards, as well as 28 technologically based hazards. Analyses revealed that the set of natural hazards; on average, were perceived to pose a moderate degree of ecological risk; similar to the set of technological hazards However, perceptions of natural hazards differed greatly from technological hazards in terms of numerous risk characteristics. In general, natural hazards: were seen as having less impact on ecosystems and on species, offering less benefits to human society, having less impact on humans, and being far less avoidable. Additional comparisons are reported, and implications for risk management and communication are discussed:

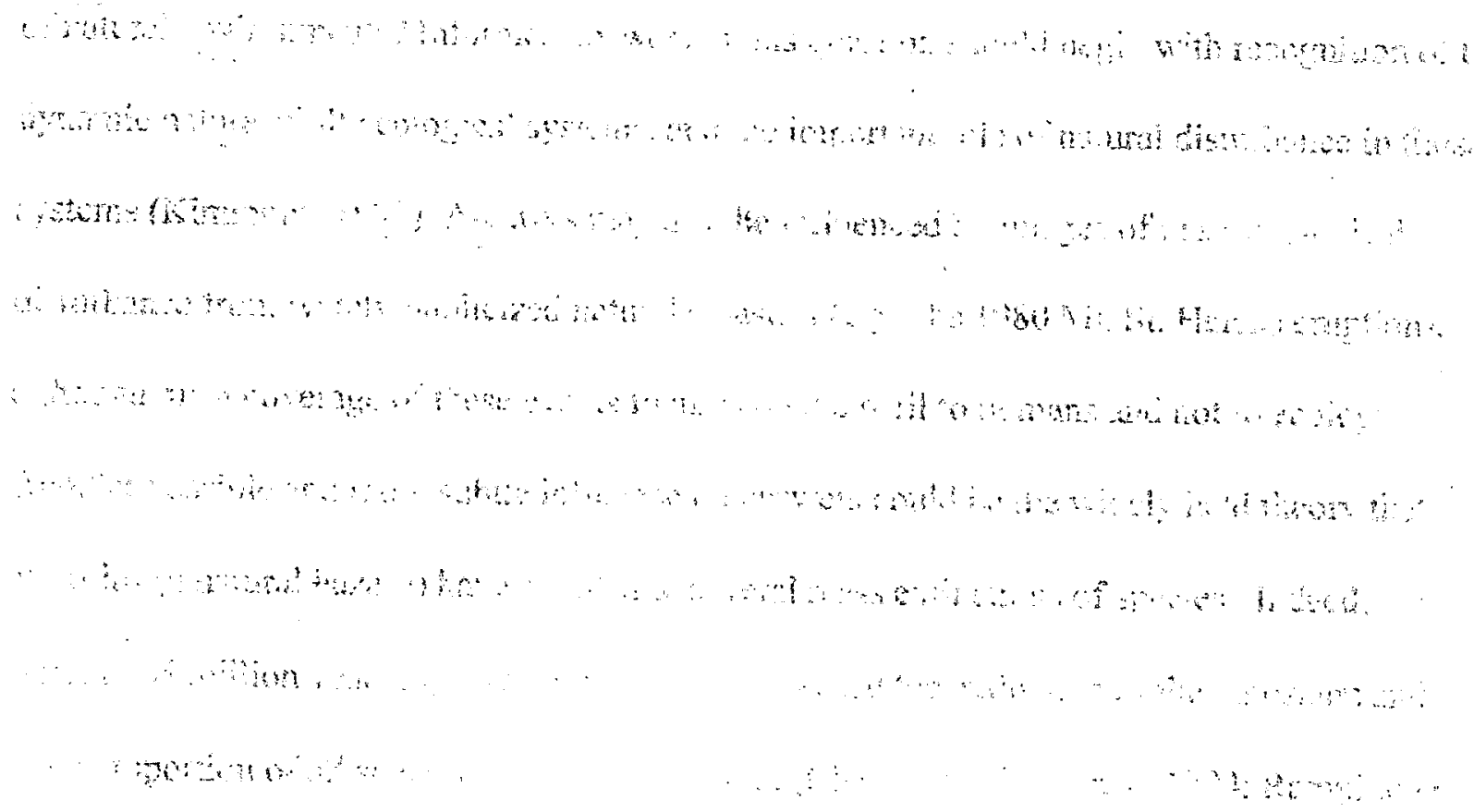


Haggerty, 1995). At the least, natural hazards can cause substantial ecological impacts. Thus, understanding how humans view differences in the ecological consequences of natural versus technological hazards merits study.

Natural hazards have been shown in previous research to be perceived as significant threats to human welfare. They have been defined as natural forces that disrupt the communities they strike. They have been characterized as sudden and unpredictable, short in duration, uncontrollable, and potentially very destructive (Bell, Fisher, Baum, \& Greene, 1990). Many factors can influence public perceptions of risk to health and property from natural hazards. Risk perceptions rise if a given hazard has occurred recently. Actions to prevent a natural disaster (e.g., building levees) or reduce the impact of a disaster (e.g., reinforcing structures against earthquakes) can greatly reduce perceived risk. People who live in areas at high risk from natural hazards appear to "learn to live" with the risk (Burton \& Kates, 1964; Kates, 1976). People also tend to protect against the most serious consequences in recent memory, rather than the consequences that analysis shows to be likely over a longer period of time (Kunreuther, et al., 1978).

The effects on humans of technological and natural hazards can be similar in many respects, particularly when the characteristics of a technological disaster parallel a natural disaster in terms of suddenness, duration, and unpredictability. Yet, research has shown that the human consequences of technological disasters are often more severe, complex, and longer lasting than those caused by natural disasters (e.g., Baum, Fleming, \& Davidson, 1983). Erikson (1990) has attributed this pattern to the perception that technological emergencies with toxic chemicals or 
radiation "never end... an 'all clear' is never sounded." Erikson also contrasts this pattern with natural disasters, which have a clear beginning, middle, and end (p. 121).

... For the most part, risk perception studies have ignored natural hazards, focusing primarily on hazardous human activities and technologies (e.g., Slovic, 1987). One study that included "storms and floods" found these hazards to be rated as a slight to moderate public health risk (Flynn, Slovic, \& Mertz, 1994). We know of no studies to date that have examined risks from both technologies and natural hazards in terms of effects on ecological health. Thus, the research presented in this article builds on prior efforts in two ways. First, it replaces human welfare with ecological welfare as the "object" of risk. Second, we include a range of hazards, including numerous technologies (e.g., nuclear power), human activities (e.g., driving automobiles), prominent environmental consequences (e.g., ozone depletion), and natural hazards (e.g., earthquakes). This approach provides a diverse range of hazards with which to explore ecological risk perception, allows comparisons among numerous specific hazards in some detail, and provides opportunities to examine how ecological risk may be perceived among different types of hazards.

Clarifying perceptions of ecological risks of natural hazards is an important step in expanding our understanding of the "social construction" and risk-management responses for natural hazards. Damage to ecological systems is a topic of growing concern for society. We know that public perceptions of risk greatly influence the extent to which society attempts to manage potential hazards to humans (Slovic, 1987). Studying perceptions of natural hazards in similar fashion may provide insights useful to the management of risks to the natural world. 


\section{CHARACTERIZING LAY PERCEPTIONS OF ECOLOGICAL RISK}

The approach we used to investigate ecological risk perception was built on the psychometric paradigm used extensively to characterize perceptions of human health risk (Slovic, 1987, 1992). This approach asks participants to rate study items (e.g., technologies, human practices that may pose risk) on various scales believed to represent characteristics of these items (e.g., perceived severity of consequences, voluntaries, level of knowledge) that may influence the judgment of overall risk. Then, multivariate statistical techniques are used to identify some underlying factors within the response patterns (e.g., dread, level of knowledge) that broadly shape those risk perceptions. Because ecological risk is inherently more complex and not as well defined as human health risk, we decided that new items and characteristics relevant to ecological risk were needed for this study. An initial step in the research was to conduct a series of focus groups to elicit the range of events people associate with ecological risk and identify the characteristics of these events that may influence risk perceptions. Participants in these focus groups included technical experts, union members, environmental activists, regional environmental managers, community residents, and university and 11 th grade high school students. An open discussion format, facilitated by one of the authors, was employed in these sessions.

Using information from the focus groups, a survey instrument was developed containing 65 items, which included five natural hazards (drought, earthquakes, floods, meteors colliding with Earth, and volcanoes), and 27 technologies and human practices (e.g., driving automobiles). The set of items also included some specific human beliefs and social systems (e.g., human dominion 
over nature, capitalism) and a range of important ecological concerns (e.g., ozone depletion, global warming, habitat loss). A complete list of items used in the present study is provided in Appendix A. The survey contained 31 scales thought to account for variance in risk perceptions ( 30 scales related to charäcteristics of the items and one general risk scale). A complete list of the scales is shown in appendix B along with the response categories provided to the respondents.

In addition to the risk perception task, participants were asked to respond to various statements regarding their views of nature and the protection of nature (see appendix C) using a .7-point scale that ranged from "strongly disagree" to "strongly agree." Ecological attitudes (worldviews) have been shown to play a role in guiding environmentally protective behavior (e.g., Axelrod \& Lehman, 1993) and in influencing perceptions of risk (Peters \& Slovic, in press).

\section{$\underline{\text { Participants, Design, and Procedures }}$}

Participants were 68 individuals ( 40 women and 28 men) recruited through advertisements from the student population at the University of British Columbia: They averaged 23 years of age and included students from most of the faculties and academic disciplines at the university. At the beginning of the survey session, participants were told that the study was concerned with how people perceive (think about and judge) various items in terms of the risk that they may pose to the "health and productivity of natural environments." Participants then rated each of the 65 items on the set of 30 characteristics and the general risk scale, with all 65 hazards rated on one characteristic before proceeding to the next one.

After completing the risk perception section of the questionnaire, participants were 
instructed to respond to the ecological worldview items. They were asked to indicate whether they agreed or disagreed with the belief statements regarding nature and its protection. The survey took respondents between 2 and 3 hours to complete, and they received either $\$ 20$ or $\$ 25$, depending on the time spent.

\section{Overall Results}

One objective of the study was to determine if a meaningful general structure for characterizing ecological risk perception could be identified. To that end, mean responses on each characteristic over all respondents for each of the 65 items were intercorrelated for all pairs of characteristics. A factor analysis of this correlation matrix provided a conceptually appealing taxonomy for characterizing ecological risk perception (McDaniels, Axelrod, \& Slovic, 1995).

Five factors, summarized in Table 1, were found to explain nearly all the variance in responses to the 30 characteristics.

Insert Table 1 about here

The first factor reflected concerns that people have regarding impacts of the items on nonhuman species. The three highest loaded characteristics on Factor 1 were "loss of animal or plant species," "infringement on the rights of species," and "amount of animal/plant suffering." Thus, we termed this factor impact on species. Correlational analyses revealed that perceived high impacts on species were strongly associated with high perceived ecological risk $(\underline{r}=.58$; $\mathrm{p}<.01)$. The second factor reflected benefits to humans derived from the item. These included 
benefits to society as a whole, as well as benefits to the individuals themselves. This factor, termed human benefits, was negatively associated with perceived risk $(\underline{\mathrm{r}}=-.51 ; \underline{\mathrm{p}}<.01)$. Thus, the more a given item was perceived as a source of benefits to humans, the less risky the event was judged. This negative relationship between perceived risk and benefit has been observed elsewhere in studies of human health risk perception (Alhakami \& Slovic, 1994). The third factor, termed impact on humans, includes influences such as the number of people affected by the item, the scope of the impact, and the relevance to individuals' lives. Higher perceptions regarding the impact on humans were associated with higher overall ecological risk perception $(\underline{\mathrm{r}}=.48 ; \underline{\mathrm{p}}<.01)$. The fourth factor reflects the avoidability of the event. Although this factor is one aspect of ecological risks are perceived by laypeople, it was found to be uncorrelated with general risk perception $(\underline{\mathrm{r}}=.02)$. The fifth factor recognizes the influence knowledge of the item has on risk judgments. For this factor, more knowledge appears to be associated with higher risk perceptions $(\underline{\mathrm{r}}=.37 ; \underline{\mathrm{p}}<.05)$.

This factor structure provides a framework for comparing risk perceptions across different risk items. The relative position of the 65 items presented in the overall study in terms of Factor 1 and Factor 3 can be seen in Figure 1. On this risk perception map, the vertical axis represents impact on species and the horizontal axis represents impact on humans. Items in the upper right quadrant are perceived as holding high ecological risks to species and humans. These items include some of the most notable environmental hazards (e.g., climate change and ozone depletion). The upper left quadrant displays items that are perceived to have less impact on humans, but relatively high impacts on nonhuman species. These hazards include the loss of 
animal and plant species, as well as the loss of wetlands, poaching, and hunting. Four of the five natural hazards fell in the lower left quadrant, reflecting lower impact on both species and humans (meteors colliding with Earth was the exception in that it was perceived to have a greater impact on species). In contrast, most of the technologies can be observed in the upper left and lower right quadrants. This risk perception map suggests that perceptions regarding the natural hazards differ substantially from perceptions of many of the technologies and human practices, as discussed in detail later. McDaniels, Axelrod, and Slovic (1995) provide a more extensive discussion of the methods, results, and risk maps for the overall ecological risk perception study.

Insert Figure 1 about here

\section{Expectations}

Based on these results, and on previous findings (e.g., Baum, Fleming, \& Davidson, 1983; Burton \& Kates, 1964; Kates, 1976), we developed some expectations about perceptions of ecological risk associated with natural hazards. We expected that respondents would perceive all five natural hazards considered in this study as (a) having a relatively low impact on species; (b) offering little or no benefits to humans, (c) having a relatively high impact on humans, (d) being unable to be avoided or controlled, and (e) having effects on natural environments that are relatively well known and understood. No substantive differences in perceptions among the five natural hazards were anticipated. It should be noted that Factor 5, knowledge of impacts, focuses on impacts resulting from a hazard and not on the probability of the hazardous event occurring. 
For example, predictability in our study refers to the ability to predict the ecological consequences of a hazard, and not the ability to predict when it may occur. Scientific literature is replete with evidence confirming the difficulties modern science has in reliably predicting the onset of natural hazards such as earthquakes (Palm, 1990).

These expectations regarding perceptions of natural hazards differ from those made regarding technologies and human practices (for reasons of simplicity this grouping will be referred to as "technologies"). We expected technologies would be perceived to have a higher impact on species (i.e., they are not naturally occurring and thus would be perceived to be "imposed" on nature and consequently more risky), and more impact on humans (the technologies and human practices affect everyday life considerably more than natural hazards). We also expected technologies to be perceived as far more avoidable, as more beneficial to humans, and as less well known or understood. In terms of a general rating of ecological risk, we presumed that the group of technologies would be considered to be more risky to natural environments than the natural hazards, although our prior knowledge of the relationship between risk and perceived benefit led us to expect that higher benefits associated with the technologies may, in fact, reduce this difference.

\section{PERCEIVED ECOLOGICAL RISK FROM NATURAL HAZARDS}

Table 2 presents the factor scores and scale means for the five natural hazards included in the study. For the "general ecological risk" scale, respondents perceived these hazards to pose a moderate risk to natural environments. All five natural hazards fell in the middle range of the 65 
total items for the general ecological risk scale (drought -27 th; earthquakes-29th;

floods - 38th; meteors - 45th; volcanoes-48th). Mean ratings of general ecological risk from natural hazards ranged between .82 (volcanoes) and 1.33 (draught) and were much lower than perceived risks from prominent ecological concerns (e.g., ozone depletion, $\underline{M}=2.51$; air pollution, $\underline{M}=2.26$ ). In contrast, the natural hazards were perceived as more risky than human activities for recreation (e.g., outdoor recreation, $\underline{M}=-1.85$; scuba diving, $\underline{M}=-1.78$ ).

Insert Table 2 about here

Turning to the underlying factors, there was a high degree of consistency among the ratings of the five natural hazards, with some exceptions. The natural hazards were perceived as offering few benefits to humans and were also rated as extremely unavoidable. In addition, the natural hazards were perceived to have only a minimal impact on species and on humans, and were judged to be relatively well understood, with two notable exceptions. Meteors colliding with Earth were seen as having a higher impact on species than the other natural hazards. These impacts were viewed as being longer in duration and less reversible than those of others hazards, likeily reflecting an awareness of the current scientific theory that a meteor colliding with the Earth contributed to the extinction of dinosaurs (Chapman \& Morrison, 1994). Second, the effects of meteors were perceived to be considerably less well known than other natural hazards: They were rated as less predictable, less observable, less recognized by experts, and rarely addressed by the media. 
Although the natural hazards were perceived as having only a limited impact on humans in terms of the factor scores in Table 2, the underlying scales show natural hazards were considered to pose a moderate risk to human health and were rated as causing a high degree of human suffering. Other characteristics contributing to this factor are the scope of the impacts and relevance to humans (which were judged low) and the number of people affected (which was rated higher). Thus, natural hazards were perceived to pose a high degree of risk to individual people, but they were not perceived as being relevant to the lives of the respondents. The scope of possible impacts on humans was seen as minimal (except for meteors).

\section{COMPARING RISK PERCEPTION OF NATURAL HAZARDS TO}

\section{TECHNOLOGIES}

\section{Comparison of Items on Selected Scales}

Table 3 provides some direct comparisons of the perceived riskiness of the sets of five natural hazards and 27 technologies considered in this study on two scales: species loss and human heaith risk. One sees that all the natural hazards were rated as substantially more risky in terms of human health than in terms of species loss. These patterns largely held for the set of technologies as well, with some notable exceptions, including biotechnology, deforestation, clear cutting forests, housing development, driftnet fishing and mass commercial fishing. Overall, the set of technologies was seen as substantially more risky in terms of species loss than the set of natural hazards. Conversely, the set of natural hazards were seen as more risky than the technologies in terms of human health. 


\section{Insert Table 3 about here}

\section{Comparisoin of Mean Ratings and Factor Scores}

Table 4 presents mean factor scores and scale ratings for the sets of natural hazards and technologies considered in the study. Column 5 in the table notes the difference between these scores. For the perception of general ecological risk scale, the set of technologies were rated as slightly more risky $(\underline{M}=1.24)$ than the natural hazards $(\underline{M}=1.07)$, but the difference was not statistically significant. Thus, both categories of hazards were perceived to pose a moderate risk to natural environments (scale ranged from -3 , "no risk," to +3 , "high risk'). Both categories were also rated as substantially less risky than potential consequences of these events (e.g., ozone depletion, $\underline{\mathrm{M}}=2.51$; loss of animal species, $\underline{\mathrm{M}}=2.53$ ). Three of the technologies were rated quite high on general risk (i.e., deforestation, $\underline{\mathrm{M}}=2.43$; untreated sewage disposal, $\underline{\mathrm{M}}=2.25$; clear-cutting forests, $\underline{M}=2.11$ ). On the other hand, several items in this set were rated as posing far less risk (e.g., transplanting species, $\underline{M}=.32$; fertilizers, $\underline{M}=.53$; air conditioning, $\underline{M}=.75$ ).

Although there was little difference in general perception of ecological risk perception between natural hazards and technologies, there was a good deal of variability in terms of the specific characteristics. As expected for Factor 1, technologies were rated as having a higher impact on species than were natural hazards. This difference stemmed, in part, from the fact that technologies were seen as responsible for the potential loss of more animal and plant species than were natural hazards, although no significant differences could be observed in terms of "destructiveness" nor in how much "animal suffering" they would cause. Other important 
components underlying differences in this factor were "ethical considerations" and "emotional response." Specifically, technologies were perceived as a greater infringement on the rights of nonhumans, were considered much less ethical, and aroused a higher degree of negative emotion than did the natural hazards. Finally, natural environments were seen as better able to adapt effectively in response to the natural hazards than to the technologies.

\section{Insert Table 4 about here}

Turning to Factor 2, technologies were perceived to offer substantially more benefits to society and to individuals than do natural hazards, also as expected. Interestingly, respondents rated the natural hazards as less "good" than the technologies, yet they were rated as more "acceptable" in terms of overall risk, although these differences were not statistically significant.

In terms of Factor 3, technologies were perceived to have a higher impact on humans than the natural hazards. Yet, this summary comparison is in some ways misleading; a review of the characteristics reveals a more complete picture. Respondents rated technologies as affecting a higher number of people and a larger area (scope), and indicated that the technologies were far more relevant to their own lives. In contrast, participants rated natural hazards as posing a higher degree of risk to human health and saw them as resulting in more human suffering. In sum, the impact of technologies on humans were seen as more widespread, whereas natural hazards were rated as posing more risk to human health. Natural hazards were also seen as more risky to human health than they were in terms of general ecological risk (1.49 compared to 1.07). In contrast, technologies were rated as posing more general ecological risk than risk to human 
health (1.24 compared to .73$)$.

Convincing evidence supporting initial expectations was also found for Factor 4, avoidability of hazards. Technologies were seen as substantially more avoidable, controllable, and easier to regulate than the natural hazards. It should be noted that respondents were asked to rate the extent that the risk itself can be controlled, regulated, and so forth, and not the impacts of the risk. Although some natural hazards (e.g., floods and drought) can sometimes be avoided with preparation (and the use of technology), apparently this distinction was not considered by our respondents.

Lastly, the impacts of the set of natural hazards were perceived to be better known in comparison to the set of technologies, although this finding is not statistically significant. Natural hazards were seen as more observable and their effects more recognized by experts than were the set of technologies. In addition, the impact of natural hazards were seen as far more immediate than those of technology, consistent with literature that describes natural hazards as "sudden" and "acute" (see Bell et al., 1990). Interestingly, the impacts of both natural hazards and technologies were considered somewhat predictable. Thus, while the timing and frequency of natural hazards may not be predictable, their consequences, when they do occur, were perceived to be relatively more observable, known, predictable, and easy to understand, than consequences of technological hazards.

In sum, although the sets of natural hazards and technologies were rated to be about equally risky, these patterns are the result of different influences. Technologies were seen as having higher impacts on both species and humans than natural hazards, both of which are positively 
correlated with general risk perception. In contrast, technologies were rated as offering more benefits to humans and their impacts were less well known and understood. Perceptions on these latter two factors offset the perceived higher impact stemming from technologies, resulting in a moderate perception of general ecological risk that does not differ greatly from that of natural hazards.

\section{Correlational Analyses}

We noted four of the five factors described in Table 1 (as well as most, if not all, of their component characteristics) were significantly correlated with general risk perceptions. These correlations describe the relationship between responses across all 65 hazards on a given characteristic or general factor as they related to perceptions of general risk across the same 65 hazards. The primary question underlying this analysis was this: As the scores on a factor (e.g., impact on species) varied across the 65 hazards was there a similar predictable pattern of responding in terms of general risk perception? In fact, for impact on species there was a significant positive correlation between the two scales $(\underline{r}=.58 ; \underline{\mathrm{p}}<.01)$, such that hazards that were rated as having a higher impact on species were also likely to be viewed as posing more risk to natural environments.

Given the differences in perceptions of the set of natural hazards as ecological risks as compared to the set of technologies, we presumed there may also be differences between these sets of hazards in the extent to which certain judgment characteristics relate to general risk perception. For example, it may be the case that perceived social or personal benefits may not be correlated with risk perceptions for natural hazards, while they may be very predictive of risks 
ascribed to technologies. Analyses discussed below examine whether the pattern of respondents' $\underline{\mathrm{N}}=68$ ) ratings on a characteristic (e.g., loss of species) vary in a systematic, predictable fashion with their response to general risk on a given hazard. To perform these analyses with respect to natural hazards and technologies, correlations between individual ratings on the 30 characteristics and their ratings on general risk were obtained initially for each hazard independently.. Mean correlations were then calculated across the five natural hazards and the 27 technologies. These means and their standard deviations are presented in Table 5.

Insert Table 5 about here

Correlations between the five highest loaded impact on species characteristics (i.e., loss of animal/plant species, infringement on the rights of species, rate of animal suffering, destructiveness, and adaptability) and general risk remained significant for both natural hazards and technologies. Nevertheless, some notable differences between natural hazards and technologies were found. First, the ethically oriented characteristics (i.e., infringement on rights and ethicality) were more highly correlated with general risk for technologies than for natural hazards. The interpretation is that the set of technologies were considered substantially less ethical than the set of natural hazards (see Table 4) and judgments on these characteristics were more highly correlated with general risk for technologies than for natural hazards. Second, ratings of the duration of impacts were more highly correlated with ratings of general risk for technologies than for natural hazards. Third, ratings of reversibility were negatively correlated $(\underline{r}=-.11)$ with general risk for natural hazards (i.e., higher ratings of reversibility were 
marginally associated with lower ratings of general risk) and were positively correlated for technologies $(\underline{\mathrm{r}}=.20)$.

Several other notable differences can be observed. First, higher correlations were found between benefits (social and personal) and general risk for technologies than for natural hazards. Thus, benefit ratings may have less influence on ecological risk judgments for the set of natural hazards than for the set of technologies. In addition, ratings of how good a hazard is and how acceptable it is are also less relevant for natural hazards than for technologies. In sum, respondents perceived little human benefit to be derived from natural hazards, and these rating were less relevant to their general judgment of risk than they were for technologies. Second, technologies were perceived as more relevant to human life and having a wider scope of impact than were natural hazards (see Table 3). Furthermore, these characteristics were significantly associated with general risk perceptions for technologies, whereas ratings on these characteristics were not significantly predictive of general risk perceptions for natural hazards. Differences between technologies and natural hazards were also found for all four avoidability characteristics. Thus, while natural hazards were seen as completely unavoidable, judgments on this factor were not predictive of general risk judgments. In contrast, technologies were seen to be avoidable, and these perceptions were positively associated with general risk perception (i.e., in particular higher ratings of avoidability and availability of alternative are associated with higher ratings of risk).

One final point concerns the influence of ecological worldview, from the worldview items in the survey, an ecological worldview scale was constructed by summing the ratings across 
items (Cronbach's Alpha $=.82$ ). Previous studies have found that worldviews are correlated with risk perceptions for technologies (Peters \& Slovic, in press). In the present study, nonsignificant positive correlation was found between respondents' ecological worldview and their ratings of general risk from natural hazards (see bottom of Table 5). In contrast, respondents' ecological worldview was predictive of ecological risks associated with technologies. This finding suggests that individuals' attitudes play a role in guiding judgments of risk (in this study risk to the health and productivity of natural environments) but only for human created risks. If a risk is naturally occurring, the influence of one's worldview on that judgment seems to be smaller. 


\section{DISCUSSION}

The findings of this study provide evidence that natural hazards are, to some extent, perceived by a lay population as risks to the health and productivity of natural environments. They are seen to have low (e.g., earthquakes) to moderate (e.g., meteors colliding with Earth) levels of impact on species, to offer little in the way of human benefits, to be unavoidable and uncontrollable, and to have impacts on natural environments that are, for the most part, well understood (the exception being meteors). In terms of human impact, natural hazards are perceived as having low (volcanoes) to moderate (earthquakes) overall impact, but are seen as posing a relatively high risk to humans and causing significant human suffering. In fact, natural hazards as a group are perceived as posing higher risks to humans than they do to nature. Earthquakes were rated as having the highest impact on humans and volcanoes the lowest in comparison to the other three natural hazards. In contrast, earthquakes were seen as having the least impact on species, whereas meteors colliding with Earth were rated as having the highest impact on species.

Perceptions of natural hazards differed significantly from perceptions of technologies on several accounts. Natural hazards were seen to have less impact on species, offer less benefits to humans, and have less overall impact on humans, although they were rated as posing significantly more risk to human health and the cause of more human suffering than were the set of technologies. The largest difference between natural hazards and technologies is in the perception of our ability to avoid or control them. Natural hazards stem from forces that are seen as quite uncontrollable. In contrast, technologies were seen by our sample as controllable, being 
particularly open to government regulation.

In addition, perceptions of risk for natural hazards appear to be influenced by different characteristics than technologies. More characteristics (23) were found to be significantly correlated with ecological risk perceptions for the set of technologies than for the set of natural hazards (15). One way of interpreting these results is that certain characteristics may be more relevant for the judgment of risk from technologies as compared to natural hazards. For natural hazards, high ratings of ecological risk are most strongly associated with perceptions of their destructiveness, the animal suffering they cause, their threat to species, and the risk they pose to human health. Although these characteristics also guide ecological risk perceptions for technologies, other considerations are also quite important. These considerations include the perceived ethical dimensions of a hazards (less ethical hazards were seen as more risky), the perceived benefits to be derived from the hazard (higher benefits are associated with less risk), and the perceived ability to avoid or control the hazard (more control paralleled higher ratings of risk).

Before turning to the implications of these findings for risk management and communication, we feel it is important to address some limitations in interpreting the present findings, particularly the correlational results. First, our sample was relatively small $(\underline{\mathrm{N}}=68)$ and does not represent a representative sample of the population. Nevertheless, our sample and research design parallel those initially used and subsequently validated in risk perception research (e.g., Slovic, 1987, 1991). Second, while we contend that the characteristics described in our study provide the basis of general perceptions of risks to nature, this is a conceptual 
argument that cannot be tested by correlational findings. For example, one can posit that perception of impacts on humans from a given hazard is a consideration people use is assessing the risk to nature resulting from the hazard. On the other hand, one could posit that the causal path flows in the reverse direction (e.g., that perceived higher risks to nature prompt higher perceived risks to humans). Another illustration of this notion can be seen in the avoidability factor. One can argue that peoples' ratings of risk for a specific technology are influenced by their perceptions of whether there are reasonable alternatives available (i.e., technologies that have alternatives are seen as more risky than technologies that do not, $\underline{r}=.40$ ). Conversely, it may be that higher perceptions of risk for a given technology produces a psychological need to find ways to reduce that risk. This desire to deal with risk leads people to recognize or create alternatives that they might not have deemed necessary if the hazard was seen as less risky. While we believe there are strong conceptual arguments for concluding that the judgment characteristics, in general, influence risk perceptions (which is why we have referred to characteristics as "influencing" risk perceptions), the correlational evidence cannot verify the causal direction of these relationships.

The findings of this study have implications for risk management and communication efforts regarding ecological risk posed by natural hazards. First, ecological disaster is part of the social construct of risks from natural hazards. While risk to humans dominates perceptions in this context, impacts on nature were also recognized by our respondents and should not be overlooked by risk managers. For example, we usually observe substantial efforts (e.g., food supply programs) in response to drought conditions in many of the less technologically 
developed countries. Very little attention seems to be paid to drought's effect on the natural landscape and its nonhuman inhabitants. Recognizing the ecological impacts of natural hazards may aid risk managers in developing more comprehensive strategies to minimize risk.

Second, the lack of perceived control over natural hazards may prompt communities to be more passive in implementing strategies to minimize damage from them, if and when they occur. Although the events themselves cannot be prevented, their impact can be greatly reduced by effective planning.

Finally, risk-communication efforts should recognize the ethical components involved in lay perceptions of risk. Ethical violations are more strongly associated with technological disasters than they are for natural disturbances. Ethical concerns are an important consideration in defining how a "risk" should be addressed. Ethical and emotional responses to certain technologies (e.g., nuclear weapons, nuclear power) certainly have led to more rigorous risk management efforts. Yet, ethical considerations may also spark exaggerated responses to certain risks (e.g., nuclear waste) in terms of effects on psychological well-being and financial expenditures. The lack of ethical components associated with natural hazards may also reduce a perceived need to implement strategies to protect ecosystems from their impact. 


\section{REFERENCES}

Alhakami, A. S., \& Slovic, P. (1994). A psychological study of the inverse relationship between perceived risk and perceived benefit. Risk Analysis, 14(6), 1085-1096.

Axelrod, L. J., \& Lehman, D. R. (1993). Responding to environmental concerns: What factors guide individual action? Journal of Environmental Psychology, 13, 144-159

Baum, A., Fleming, R., \& Davidson, L. M. (1983). Natural hazards and technological catastrophe. Environment and Behavior, 15, 333-354.

Bell, P. A., Fisher, J. P., Baum, A., \& Greene, T. C. (1990). Environmental psychology (3rd ed.). New York: Holt, Rinehart, \& Winston.

Burton, I., \& Kates, R. W. (1964). Perceptions of hazards in resource management. Natural Resources Journal, 3, 412-441.

Chapman, C. R., \& Morrison, D. (1994). Impacts on the Earth by asteroids and comets: Assessing the hazard. Nature, 367, 33-40.

Erikson, K. (1990, January-February). Toxic reckoning: Business faces a new kind of fear. Harvard Business Review, pp. 118-126.

Flynn, J., Slovic, P., \& Mertz, C. K. (1994). Gender, race, and perception of environmental health risks. Risk Analysis, 14(6), 1101-1108.

Kates, R. W. (1976). Experiencing the environment as hazard. In H. M. Probbansky, W. H. Ittelson, \& L. G. Rivlin (Ed.), Environmental psychology: People and their physical settings (2nd ed.). New York: Holt, Rinehart, \& Winston.

Kimmins, H. (1992). Balancing act: Environmental issues in forestry. Vancouver, BC: University of British Columbia.

Kunreuther, H., Ginsberg, R., Miller, L., Sagi, P., Slovic, P., Borkan, B., \& Katz, N. (1978). Disaster insurance protection: Public policy lessons. New York: Wiley.

McDaniels, T., Axelrod, L. J., \& Slovic, P. (1995). Characterizing perception of ecological risk. Risk Analysis, 15(5), 575-588. 
Palm, R. I. (1990). Natural hazards: An integrative framework for research and planning. Baltimore: Johns Hopkins.

Peters, E., \& Slovic, P. (In press). The role of affect and worldviews as orienting dispositions in the perception and acceptance of nuclear power. Journal of Applied Social Psychology.

Rampino, M. R., \& Haggery, B. M. (1994). Extraterrestrial impacts and mass extinctions of life. In T. Gehrels (Ed.), Hazards due to comets and asteroids (pp. 827-857). Tucson, AZ: University of Arizona.

Slovic, P. (1987). Perception of risk. Science, 236, 280-285.

Slovic, P. (1991). Perceived risk, trust, and the politics of nuclear waste. Science, 254, 16031607.

Slovic, P. (1992). Perception of risk: Reflections on the psychometric paradigm. In S. Krimsky \& D. Golding (Eds.), Social theories of risk (pp. 117-152). New York: Praeger. 
Table 1. Underlying Factors Characterizing Lay Perceptions of Ecological Risks

\begin{tabular}{ll}
\hline Factor label & $\begin{array}{c}\text { Percent variance accounted } \\
\text { for by factor }\end{array}$ \\
\hline 1. $\quad \begin{array}{l}\text { Impact of species (i.e., loss of animal species, rate } \\
\text { of animal suffering, infringement on rights of } \\
\text { species, destructiveness, ability of nature to adapt, } \\
\text { reversibility of impacts, duration of impacts, } \\
\text { negative emotions, ethicality of event, certainty of } \\
\text { impacts) }\end{array}$ & $56 \%$ \\
2. $\quad \begin{array}{l}\text { Human benefits (i.e., benefits to society, benefits } \\
\text { to individuals, overall goodness of event, } \\
\text { equitableness of distribution of costs/benefits, } \\
\text { overall acceptability of event, rate of human } \\
\text { suffering) }\end{array}$ & 18 \\
3. $\quad \begin{array}{l}\text { Impact on humans (i.e., number of people } \\
\text { affected, relevance to individual's life, scope of } \\
\text { area effected, risks to human health) }\end{array}$ & 9 \\
4. $\quad \begin{array}{l}\text { Avoidability (i.e., controllability of risk, } \\
\text { availability of alternatives, avoidability of impacts, } \\
\text { ability to regulate risk) }\end{array}$ & 5 \\
5. $\quad \begin{array}{l}\text { Knowledge (i.e., observability of risk, } \\
\text { predictability of impacts, experts recognition of } \\
\text { impacts, understandability of impacts, immediacy } \\
\text { of impacts, media coverage) }\end{array}$ & 3 \\
\hline
\end{tabular}

Note. $\underline{N}=68 ;$ from McDaniels, Axelrod, \& Slovic (1995). 
Perceptions of Ecological Risk From Natural Hazards

page 28

Table 2. Mean Ratings of Natural Hazard Items on Individual Characteristics and General Factor Scores

\begin{tabular}{|c|c|c|c|c|c|}
\hline Factor & Earthquakes & Floods & Drought & Volcanoes & Meteors \\
\hline Factor 1: Impact on species & -1.75 & -1.29 & -.95 & -.60 & .32 \\
\hline Loss of animal and plant species & -.41 & -.17 & .34 & -.40 & .29 \\
\hline Infringement on rights of species & .01 & .10 & .18 & -.36 & -.56 \\
\hline Rate of animal suffering & 1.45 & 1.44 & 1.65 & 1.28 & .88 \\
\hline Destructiveness of impacts & .73 & .69 & 1.00 & .75 & .79 \\
\hline Ability of nature to adapt & .11 & -.13 & -.69 & .03 & -.15 \\
\hline Reversibility of impacts & .57 & .68 & .54 & -.25 & -.81 \\
\hline Duration of impacts & -.64 & -.53 & -.22 & -.35 & .31 \\
\hline Negative emotions aroused & -.06 & -.42 & -.18 & -1.10 & -1.21 \\
\hline Ethicality of hazard & .42 & .42 & .30 & .52 & .48 \\
\hline Certainty of impacts & 1.49 & 1.07 & 1.75 & 1.24 & .38 \\
\hline Factor 2: Benefits to humans & -1.10 & -1.08 & -.91 & -.77 & -1.03 \\
\hline Benefits for society & -2.68 & -2.53 & -2.58 & -2.25 & -2.49 \\
\hline Benefits for individuals & -2.90 & -2.86 & -2.83 & -2.78 & -2.82 \\
\hline Goodness of event & -1.81 & -1.74 & -1.74 & -1.16 & -1.57 \\
\hline Fquity of costs/benefits & -1.16 & -1.10 & -1.17 & -1.08 & -1.02 \\
\hline Overall acceptability of risk & -.33 & -.20 & -.43 & -.10 & -.22 \\
\hline Factor 3: Impact on humans & -.10 & -.71 & -.57 & -1.36 & -.89 \\
\hline Number of people affected & .64 & .29 & .51 & -.50 & .59 \\
\hline Relevance to humans & -.04 & -.85 & -.76 & -1.43 & -1.24 \\
\hline Scope of area affected & -1.08 & -1.01 & -.82 & -.99 & .71 \\
\hline Risk to human health & 1.97 & 1.55 & 1.89 & .96 & 1.09 \\
\hline Rate of human suffering & 2.10 & 1.81 & 1.90 & 1.39 & .94 \\
\hline Factor 4: Avoidability & -2.58 & -2.57 & -2.44 & -2.92 & -3.48 \\
\hline Controllability if impacts & -2.71 & -2.26 & -2.17 & -2.75 & -2.83 \\
\hline Avoidability of impacts & -2.71 & -2.41 & -2.32 & -2.68 & -2.59 \\
\hline Availability of alternatives & -2.58 & -2.44 & -2.22 & -2.33 & -2.49 \\
\hline Ability to regulate hazard & -2.69 & -2.79 & -2.55 & -2.75 & -2.70 \\
\hline Factor 5: Knowledge of impacts & 1.90 & 1.39 & 1.51 & .81 & -1.72 \\
\hline Observability & 2.13 & 1.86 & 1.90 & 1.64 & .64 \\
\hline Predictability of impacts & 1.04 & .92 & 1.21 & .65 & -.14 \\
\hline Experts recognition of impacts & 2.11 & 2.03 & 2.15 & 1.85 & .79 \\
\hline Understandability of hazard & -2.04 & -1.76 & -1.90 & -1.90 & -1.14 \\
\hline Immediacy of impacts & -2.39 & -2.36 & -1.93 & -1.97 & -1.62 \\
\hline Extent of media coverage of hazard & 1.76 & 1.12 & .81 & .11 & -1.56 \\
\hline General rating of risk & 1.28 & 1.04 & 1.33 & .82 & .89 \\
\hline
\end{tabular}

Note. Values for the characteristics and general risk are mean ratings on 7-point scales, rescaled to range from -3 to +3 . Values for the factors are calculated factor scores generated using factor analysis procedures. 
Table 3. Mean Ratings of Natural and Technological Hazard Items on Scales For Risk To Human Health and Species Loss

\begin{tabular}{|c|c|c|c|c|}
\hline & \multicolumn{2}{|c|}{$\begin{array}{c}\text { Risk to } \\
\text { human health }\end{array}$} & \multicolumn{2}{|c|}{ Species loss } \\
\hline$x^{\prime}$ & Mean & $\mathrm{SD}$ & Mean & $\mathrm{SD}$ \\
\hline \multicolumn{5}{|l|}{ Natural Hazards } \\
\hline 1. Drought & 1.89 & $(1.35)$ & 0.34 & $(1.72)$ \\
\hline 2. Earthquakes & 1.97 & $(1.35)$ & -0.41 & $(1.83)$ \\
\hline 3. Floods & 1.55 & $(1.49)$ & -0.17 & $(1.81)$ \\
\hline 4. Meteors colliding with Earth & 1.09 & $(2.02)$ & 0.29 & $(2.20)$ \\
\hline 5. Volcanos & 0.96 & $(1.95)$ & -0.40 & $(1.65)$ \\
\hline
\end{tabular}

Technologies and Human Practices

1. Aerosol Cans

2. Air Conditioning

3. Biotechnology

4. Burning of waste (incineration)

5. Clearcutting

6. Dams

7. Deforestation

8. Development of housing

9. Landfills

10. Treated sewage disposal

11. Untreated sewage disposal

12. Driftnet fishing

13. Driving of automobiles

14. Emission ofozone-zone depleting gases (CFCs)

15. Energy production

16. Fertilizers

17. Mass commercial fishing

18. Irrigated agriculture

19. Mass farming

20. Mining

21. Nuclear power plants

22. Pesticides

23. Toxic waste

24. Transplanting of species

25. Oil transportation

26. Urban water use

27. Waste production

$\begin{array}{rrrr}1.50 & (1.50) & 0.85 & (1.62) \\ 0.71 & (1.73) & 0.10 & (1.78) \\ 0.29 & (1.62) & 1.08 & (1.62) \\ 1.04 & (1.57) & 0.28 & (1.73) \\ 0.92 & (1.70) & 1.89 & (1.16) \\ -0.32 & (1.55) & 0.76 & (1.60) \\ 1.07 & (1.77) & 2.36 & (1.06) \\ -0.37 & (1.54) & 1.20 & (1.19) \\ 0.82 & (1.52) & 0.11 & (1.68) \\ 0.85 & (1.52) & 0.79 & (1.64) \\ 1.93 & (1.18) & 1.75 & (1.39) \\ 0.03 & (1.81) & 1.01 & (1.58) \\ 1.56 & (1.21) & 0.42 & (1.73) \\ 1.99 & (1.24) & 1.22 & (1.62) \\ 1.01 & (1.56) & 0.27 & (1.63) \\ 0.36 & (1.40) & -0.06 & (1.49) \\ 0.08 & (1.70) & 1.30 & (1.33) \\ -0.51 & (1.67) & 0.00 & (1.67) \\ 0.01 & (1.65) & 0.47 & (1.77) \\ 0.48 & (1.47) & -0.31 & (1.62) \\ 1.60 & (1.53) & 0.67 & (1.77) \\ 0.97 & (1.33) & 0.69 & (1.35) \\ 1.85 & (1.08) & 1.30 & (1.57) \\ -0.28 & (1.49) & 0.24 & (1.56) \\ 0.42 & (1.54) & 0.58 & (1.54) \\ 0.23 & (1.65) & -0.07 & (1.81) \\ 1.54 & (1.39) & 0.90 & (1.72)\end{array}$


Perceptions of Ecological Risk From Natural Hazards page 30

Table 4. Mean Ratings of Natural Hazard Items Compared to Mean Ratings of Technological Hazards on Individual Characteristics and General Factor Scores

\begin{tabular}{|c|c|c|c|c|c|}
\hline \multirow[b]{2}{*}{ Factor } & \multicolumn{2}{|c|}{ Natural hazards } & \multicolumn{2}{|c|}{ Technological hazards } & \multirow{2}{*}{$\begin{array}{c}\text { Mean } \\
\text { Difference }\end{array}$} \\
\hline & Mean & SD & Mean & SD & \\
\hline Factor 1: Impact on species & -.85 & .78 & -.02 & .57 & $.83^{* *}$ \\
\hline Loss of animal and plant species & -.07 & .36 & .73 & .65 & $.80^{*}$ \\
\hline Infringement on rights of species & -.13 & .32 & 1.47 & .62 & $1.60 * * *$ \\
\hline Rate of animal suffering & 1.34 & .29 & 1.33 & .57 & .01 \\
\hline Destructiveness of impacts & .79 & .12 & .96 & .60 & .17 \\
\hline Ability of nature to adapt & -.17 & .31 & -.92 & .62 & $.75^{*}$ \\
\hline Reversibility of impacts & .15 & .65 & -.34 & .46 & $.49^{*}$ \\
\hline Duration of impacts & -.29 & .37 & 1.49 & .51 & $1.78 * * *$ \\
\hline Negative emotions aroused & -.59 & .53 & .60 & .88 & $1.19^{* *}$ \\
\hline Ethicality of hazard & .43 & .08 & -.86 & .73 & $1.29 * * *$ \\
\hline Certainty of impacts & 1.19 & .52 & 1.73 & .53 & $.54^{*}$ \\
\hline Factor 2: Benefits to humans & -.98 & .14 & .33 & .92 & $1.22 * *$ \\
\hline Benefits for society & -2.51 & .16 & -.51 & 1.07 & $2.00 * * *$ \\
\hline Benefits for individuals & -2.84 & .04 & -.88 & 1.07 & $1.96^{* * *}$ \\
\hline Goodness of the item & -1.60 & .26 & -1.22 & .76 & .38 \\
\hline Equity of costs/benefits & -1.11 & .06 & -.65 & .49 & $.46^{*}$ \\
\hline Overall acceptability of risk & -.26 & .13 & -.94 & .78 & .68 \\
\hline Factor 3: Impact on humans & -.73 & .46 & .17 & .69 & $.90^{* *}$ \\
\hline Number of people affected & .31 & .47 & 1.09 & .56 & $.78^{* *}$ \\
\hline Relevance to humans & -.86 & .54 & .75 & .67 & $1.61^{* * *}$ \\
\hline Scope of area affected & -.64 & .76 & .77 & .71 & $1.41 * * *$ \\
\hline Risk to human health & 1.49 & .46 & .73 & .74 & $.76^{*}$ \\
\hline Rate of human suffering & 1.63 & .46 & .50 & .67 & $1.13^{* *}$ \\
\hline Factor 4: Avoidability & -2.79 & .41 & .48 & .46 & $3.27 * * *$ \\
\hline Controllability if impacts & -2.54 & .31 & 1.12 & .37 & $3.66 * * *$ \\
\hline Avoidability of impacts & -2.54 & .17 & .58 & .92 & $3.12 * * *$ \\
\hline Availability of alternatives & -2.41 & .14 & 1.26 & .61 & $3.67 * * *$ \\
\hline Ability to regulate hazard & -2.70 & .09 & 1.63 & .34 & $4.33^{* * *}$ \\
\hline Factor 5: Knowledge of impacts & .78 & 1.45 & .27 & .92 & .51 \\
\hline Observability & 1.64 & .58 & .55 & .81 & $1.09^{* *}$ \\
\hline Predictability of impacts & .74 & .53 & .88 & .49 & .14 \\
\hline Experts recognition of impacts & 1.79 & .57 & .23 & .49 & $1.56^{* * *}$ \\
\hline Understandability of hazard & -1.75 & .35 & -1.11 & .55 & $.64^{*}$ \\
\hline Immediacy of impacts & -2.05 & .32 & -.56 & .46 & $1.49^{* * *}$ \\
\hline Extent of media coverage of hazard & .45 & 1.27 & .39 & .91 & .06 \\
\hline General rating of risk & 1.07 & .23 & 1.24 & .58 & .17 \\
\hline
\end{tabular}

Note. Values for the characteristics and general risk are mean ratings on 7-point scales, rescaled to range from -3 to +3 . Values for the factors (SD) are calculated factor scores generated using factor analysis procedures. ${ }^{*} \mathrm{~g}<.05$;

${ }^{* *} \mathrm{p}<.01 ;{ }^{* * *} \mathrm{p}<.001$. 
Table 5. Mean Correlation Coefficients Between Characteristics and General Risk Perception Across Respondents for Sets of Natural and Technological Hazards

\begin{tabular}{lrcrl}
$\frac{\text { Natural hazards }}{(\underline{n}=5)}$ & & \multicolumn{2}{c}{ Technological hazards } \\
${ } }$ & SD & Mean & SD & Difference \\
\hline
\end{tabular}

Characteristics
Factor 1: Impact on species

Loss of animal and plant species

Infringement on rights of species

Rate of animal suffering

Destructiveness of impacts

Ability of nature to adapt

Reversibility of impacts

Duration of impacts

Negative emotions aroused

Ethicality of hazard

Certainty of impacts

SD

Mean

$\begin{array}{rrrll}.41 & .03 & .48 & .11 & .07 \\ .36 & .04 & .52 & .12 & .16^{* *} \\ .54 & .07 & .58 & .08 & .04 \\ .59 & .07 & .55 & .10 & .04 \\ -.41 & .05 & -.43 & .14 & .02 \\ -.11 & .08 & .20 & .10 & .31^{* * *} \\ .15 & .05 & .36 & .11 & .21^{* * *} \\ .45 & .07 & .61 & .10 & .16^{* *} \\ -.21 & .04 & -.51 & .10 & .30^{* * *} \\ .26 & .13 & .35 & .15 & .09\end{array}$

Factor 2: Benefits to humans

Benefits for society

Benefits for individuals

Goodness of event

$-.22$

.09

$-.36$

.12

$-.29$

.12

$-.02$

.10

$-.58$

.11

Equity of costs/benefits

$-.16$

$-.22$

.11

Overall acceptability of risk

$-.39$

$-.64$

.09

Factor 3: Impact on humans

Number of people affected

Relevance to humans

Scope of area affected

Risk to human health

Rate of human suffering

.18
.09
.18
.07
.08

.38
.30
.37
.59
.55

Factor 4: Avuidability

Controliability if impacts

Avoidability of impacts

$$
-.09
$$

Availability of alternatives

Ability to regulate hazard

Factor 5: Knowledge of impacts

$\begin{array}{rrrrl}.24 & .06 & .30 & .13 & .06 \\ .34 & .10 & .32 & .12 & .02 \\ .15 & .12 & .13 & .12 & .02 \\ -.34 & .11 & -.36 & .09 & .02 \\ .02 & .09 & -.16 & .12 & .18^{* *} \\ .32 & .09 & .16 & .15 & .16^{*}\end{array}$

Observability

Predictability of impacts

Experts recognition of impacts

Understandability of hazard

Immediacy of impacts

Extent of media coverage of hazard

.09

.21

\section{.}




\section{APPENDIX A: List of Natural Hazards, Technologies, and Human Practices in Survey}

Natural hazards

1. Drought

2. Earthquakes

3. Floods

4. Meteors colliding with Earth

5. Volcanoes

Technologies and human practices

1. Aerosol cans

2. Air conditioning

3. Biotechnology

4. Burning of waste (incineration)

5. Clearcutting

6. Dams

7. Deforestation

8. Development of housing

9. Landfills

10. Treated sewage disposal

11. Untreated sewage disposal

12. Driftnet fishing

13. Driving of automobiles

14. Emission of ozone depleting gases (CFCs)

15. Energy production

16. Fertilizers

17. Mass commercial fishing

18. Irrigated agriculture

19. Mass farming

20. Mining

21. Nuclear power plants

22. Pesticides

23. Toxic waste

24. . Transplanting of species

25. Oil transportation

26. Urban water use

27. Waste production 


\section{APPENDIX B: Description of Characteristics and Response Categories}

\begin{tabular}{|c|c|c|}
\hline \multirow[b]{2}{*}{ Description of scale } & \multicolumn{2}{|l|}{ Scale end points } \\
\hline & Low & High \\
\hline $\begin{array}{l}\text { CERTAINTY: Please rate how } \\
\text { certain it is that the event has an } \\
\text { impact on natural environments }\end{array}$ & Not at all certain & Very certain \\
\hline $\begin{array}{l}\text { ADAPTABILITY: Please rate how } \\
\text { well natural environments maintain } \\
\text { their health and productivity in } \\
\text { response to the current level of each } \\
\text { event }\end{array}$ & Cannot at all maintain & Can fully maintain \\
\hline $\begin{array}{l}\text { AVOIDABILITY: Please rate how } \\
\text { avoidable the event is, in terms of } \\
\text { how easy or difficult it would be to } \\
\text { avoid the occurrence of the event }\end{array}$ & Not at all avoidable & Completely avoidable \\
\hline $\begin{array}{l}\text { RELEVANCE TO YOUR LIFE: } \\
\text { Please rate how relevant the event is } \\
\text { to your life, in terms of its impact on } \\
\text { natural environments }\end{array}$ & No relevance & Direct relevance \\
\hline $\begin{array}{l}\text { CONTROLLABILITY: Please rate } \\
\text { how controllable is each event, in } \\
\text { terms of people's ability to control } \\
\text { its impact on natural environments }\end{array}$ & Not at all controllable & Very controllable \\
\hline $\begin{array}{l}\text { DURATION OF IMPACTS: Please } \\
\text { rate the duration of the impacts that } \\
\text { each event has on natural } \\
\text { environments }\end{array}$ & Short-term impacts & Long-term impacts \\
\hline $\begin{array}{l}\text { SOCIETAL BENEFITS: Please rate } \\
\text { how much you think the event may } \\
\text { benefit the functioning of your } \\
\text { society }\end{array}$ & No social benefit & Great social benefit \\
\hline $\begin{array}{l}\text { PERSONAL BENEFITS: Please } \\
\text { rate how much you think that you } \\
\text { personally can or do benefit from the } \\
\text { event }\end{array}$ & No personal benefit & Great personal benefit \\
\hline
\end{tabular}




\begin{tabular}{lll}
\hline & Scale end points & \\
\cline { 2 - 3 } Description of scale & Low & High \\
\hline $\begin{array}{l}\text { SCOPE OF IMPACTS: Please rate } \\
\text { the scope of the impacts of the }\end{array}$ & Small local effects & Widespread global effects \\
event, in terms of the size of the area \\
affected
\end{tabular}




\begin{tabular}{|c|c|c|}
\hline \multirow[b]{2}{*}{ Description of scale } & \multicolumn{2}{|l|}{ Scale end points } \\
\hline & Low & High \\
\hline $\begin{array}{l}\text { INFRINGEMENT ON RIGHTS: } \\
\text { Please rate to what extent the event } \\
\text { infringes on the rights of nonhuman } \\
\text { species }\end{array}$ & Does not infringe & Greatly infringes \\
\hline $\begin{array}{l}\text { REVERSIBILITY OF IMPACTS: } \\
\text { Please rate the extent to which the } \\
\text { impacts on natural environments } \\
\text { associated with the event are } \\
\text { reversible (i.e., the ability of natural } \\
\text { environments to return to pre-event } \\
\text { conditions) }\end{array}$ & Completely irreversible & Completely reversible \\
\hline $\begin{array}{l}\text { HUMAN SUFFERING: Please rate } \\
\text { how much human suffering could } \\
\text { result from the event as a result of its } \\
\text { impact on natural environments }\end{array}$ & No suffering & Great suffering \\
\hline $\begin{array}{l}\text { ANIMAL/PLANT SUFFERING: } \\
\text { Please rate how much suffering by } \\
\text { animals or plants could occur as a } \\
\text { result of the event }\end{array}$ & No suffering & Great suffering \\
\hline $\begin{array}{l}\text { UNDERSTANDABILITY: Please } \\
\text { rate how easy or difficult it is to } \\
\text { understand the impacts each event } \\
\text { has on natural environments }\end{array}$ & Simple to understand & Hard to understand \\
\hline $\begin{array}{l}\text { PREDICTABILITY: Please rate } \\
\text { how well impacts on natural } \\
\text { environments associated with the } \\
\text { event can be predicted }\end{array}$ & Not at all predictable & Very predictable \\
\hline $\begin{array}{l}\text { RECOGNITION OF IMPACTS: } \\
\text { Please rate how recently potential } \\
\text { impacts on natural environments } \\
\text { associated with each event have } \\
\text { been recognized by experts }\end{array}$ & Recognized recently & Recognized for a long time \\
\hline
\end{tabular}




Description of scale
OBSERVABILITY OF IMPACTS:
Please rate how observable are the
impacts on natural environments
associated with the event
MEDIA ATTENTION: Please rate
how much attention the media has
given to the event, in terms of its
impact on natural environments
REGULATABILITY OF RISK:
Please rate the extent to which the
event can be regulated by
governments

AVAILABILITY OF ALTERNATIVES: Please rate the extent to which there are reasonable alternatives to the event, or to the practices that lead to the event

GOODNESS: Please rate whether you think, in general, the event is good or bad

HUMAN HEALTH RISK: Please rate the extent to which the event and its impact on natural environments pose a risk to human health

GENERAI ACCEPTABILITY OF EVENT: Please rate the acceptability of each event, in terms of its general impact on human life and natural environments

GENERAL RISKINESS: Please rate how "risky in general" you think each event is in terms of its impacts on the health and productivity of natural environments
Scale end points

Low High

No attention

A great deal of attention

Cannot be regulated

Can be completely regulated

Alternatives not available

Alternatives are available

Very bad

Very good

No risk

A great risk

Not at all

Completely

Poses no risk

Poses great risk 


\section{APPENDIX C: Description of Ecological Worldview Scale}

Participants were asked to indicate their agreement to the following statements on a scale that ranged from 1 (strongly disagree) TO 7 (strongly agree).

1. It is more important for human life to progress than it is to protect animal or plant life.

2. The resources of the earth exist for the use of humankind.

3. Environmental protection must not stand in the way of providing economic opportunity for everyone.

4. The earth will always be able to provide the resources necessary for the human race to survive.

5. The behavior of humans needs to become more sensitive to the environment if the human race is to survive.

6. The extinction of animal and plant species is acceptable as long as alternative resources exist. 
Reference note:

Kates 1976 still needs page numbers 